\title{
PUBLIC TALK | More Than A Century Of Crystallography: What Has It Taught Us And Where Will It Lead?
}

Garman, Elspeth (University of Oxford, Oxford, GBR)

What has the art of the chocolatier got to do with drug discovery, proteins and DNA? The linking theme is crystals, which allow us to determine the three-dimensional shapes of all sizes of molecules, ranging from the tiny chocolate moiety to the much larger proteins that allow our bodies to function through to the DNA that carries our genetic information. Crystallography was born in 1913 with the determination of the 3-D structure of sodium chloride (salt) by the Bragg father and son team. It has flowered to elucidate many disciplines since then, with applications in engineering, physics, chemistry, earth sciences and biology. Using crystallography, we can unravel the shapes of biomolecules in our bodies that are targets for drugs against disease, and thus identify new treatments. I will focus on this last field, and give an overview of what is currently achievable and what may be possible in the future (my crystal ball permitting!). 